\title{
A Simple Proof of Suzumura's Extension Theorem for Finite Domains With Applications
}

\author{
SOMDEB LAHIRI ${ }^{\dagger}$ \\ 060lah@mentor.edcm.wits.ac.za \\ Indian Institute of Management, Ahmedabad, India and School of Economic and Busi- \\ ness Sciences, University of Witwatersrand at Johannesburg, South Africa.
}

\begin{abstract}
In this paper we provide a simple proof of the extension theorem for partial orderings due to Suzumura [1983] when the domain of the partial order is finite. The extension theorem due to Szpilrajn [1930] follows from this theorem. Szpilrajns extension theorem is used to show that an asymmetric binary relation is contained in the asymmetric part of a linear order if and only if it is acyclic. This theorem is then applied to prove three results. Finally we introduce the concept of a threshold choice function, and our third result says that such choice functions are the only ones to satisfy a property called functional acyclicity.
\end{abstract}

Keywords: Partial Orderings, Extension Theorem, Threshold Choice Function.

\section{Introduction}

In this paper we provide a simple proof of the extension theorem for partial orderings due to Suzumura [1983] when the domain of the partial order is finite. The extension theorem due to Szpilrajn [1930] follows from this theorem. Szpilrajn's extension theorem is used to show that an asymmetric binary relation is contained in the asymmetric part of a linear order if and only if it is acyclic. This theorem is then applied to prove three results. The first result implied by two theorems in Aizerman and Malishevsky [1981], (see Aizerman and Aleskerov [1995] as well) says that the asymmetric part of a quasi-transitive binary relation can be expressed as the intersection of the asymmetric parts of orders. The well known result due to Dushnik and Miller [1941], which states that any asymmetric and transitive binary relation is the intersection of linear orders follows as an immediate corollary of this result. The second result is a theorem in Lahiri [1999], which says that a choice function is a batch choice function if and only if it satisfies a property called the choice acyclicity property. We provide a new proof

$\dagger$ Requests for reprints should be sent to Somdeb Lahiri, School of Economic and Business Sciences, University of Witwatersrand at Johannesburg, Private Bag 3, WITS 2050, South Africa. 
of this result. The concept of a batch choice function can be found in Aizerman and Aleskerov [1995] and in recent times it has been applied in the study of stable matching problems. Finally we introduce the concept of a threshold choice function, and our third result says that such choice functions are the only ones to satisfy a property called functional acyclicity. This last property can be traced to Aizerman and Aleskerov [1995] as well.

\section{The Extension Theorems}

Let $\mathrm{X}$ be a finite, non-empty set. Given a binary relation $\mathrm{R}$, let $\mathrm{P}(\mathrm{R})=$ $\{(\mathrm{x}, \mathrm{y}) \in \mathrm{R} /(\mathrm{y}, \mathrm{x}) \notin \mathrm{R}\}$ and $\mathrm{I}(\mathrm{R})=\{(\mathrm{x}, \mathrm{y}) \in \mathrm{R} /(\mathrm{y}, \mathrm{x}) \in \mathrm{R}\} . \mathrm{P}(\mathrm{R})$ is called the asymmetric part of $\mathrm{R}$ and $\mathrm{I}(\mathrm{R})$ is called the symmetric part of $\mathrm{R}$. A binary relation $\mathrm{R}$ on $\mathrm{X}$ is said to be (a) reflexive if $\forall x \in X:(x, x) \in R$; (b) complete if $\forall x, y \in X$ with $x \neq y$, either $(x, y) \in R$ or $(y, x) \in R$; (c) transitive if $\forall x, y, z \in \mathrm{X},[(\mathrm{x}, \mathrm{y}) \in \mathrm{R} \&(\mathrm{y}, \mathrm{z}) \in \mathrm{R}$ implies $(\mathrm{x}, \mathrm{z}) \in \mathrm{R}] ;$ (d) asymmetric if $\forall \mathrm{x}, \mathrm{y} \in \mathrm{X}:(\mathrm{x}, \mathrm{y}) \in \mathrm{R}$ implies $(\mathrm{y}, \mathrm{x}) \notin \mathrm{R}$; (e) quasi-transitive if $\forall \mathrm{x}, \mathrm{y}, \mathrm{z} \in \mathrm{X},(\mathrm{x}, \mathrm{y}) \in \mathrm{P}(\mathrm{R})$ and $(\mathrm{y}, \mathrm{z}) \in \mathrm{P}(\mathrm{R})$ implies $(\mathrm{x}, \mathrm{z}) \in \mathrm{P}(\mathrm{R})$. Given a binary relation $\mathrm{R}$ on $\mathrm{X}$ a binary relation $\mathrm{Q}$ on $\mathrm{X}$ is said to extend (be an extension of) $\mathrm{R}$ if $\mathrm{R} \subset \mathrm{Q}$ and $\mathrm{P}(\mathrm{R}) \subset \mathrm{P}(\mathrm{Q})$.

A binary relation $\mathrm{R}$ on $\mathrm{X}$ is said to be a partial order if it is reflexive and transitive. It is said to be an order if it is a complete partial order. A binary relation $\mathrm{R}$ on $\mathrm{X}$ is said to be a linear order if it is an order and further $\mathrm{I}(\mathrm{R})=\Delta_{X} \equiv\{(\mathrm{x}, \mathrm{x}) / \mathrm{x} \in \mathrm{X}\}$.

Given a binary relation $\mathrm{R}$ on $\mathrm{X}$ and given any non-empty subset $\mathrm{S}$ of $\mathrm{X}$, let $\mathrm{M}(\mathrm{S}, \mathrm{R})$ denote $\{\mathrm{x} \in \mathrm{S} /(\mathrm{y}, \mathrm{x}) \in \mathrm{P}(\mathrm{R})$ implies $\mathrm{y} \notin \mathrm{S}\}$.

Given a binary relation $\mathrm{R}$ on $\mathrm{X}$ define binary relations $T(R)\left(: T^{\circ}(R)\right)$ on $X$ as follows: $(\mathrm{x}, \mathrm{y}) \in T(R))\left(: T^{\circ}(R)\right)$ if and only if there exists a positive integer $\mathrm{K}$ and $\mathrm{x}_{1}, \ldots, \mathrm{x}_{K}$ in $\mathrm{X}$ with (i) $\mathrm{x}_{1}=\mathrm{x}, \mathrm{x}_{K}=\mathrm{y}:$ (ii) $\left(x_{i}, x_{i+1}\right) \in$ $R \forall i \in\{1, \ldots, K-1\}$ (:and $\left(x_{i}, x_{i+1}\right) \in P(R)$ for $\left.i \in\{1, \ldots, K-1\}\right)$. T(R) is called the transitive hull of R. Clearly $\mathrm{T}(\mathrm{R})$ is always transitive. Further $T(I(R)) \subset I(T(R))$. Note that $T(R) \backslash T(I(R)) \subset T^{\circ}(R)$

A binary relation $\mathrm{R}$ on $\mathrm{X}$ is said to be acyclic if $\mathrm{T}(\mathrm{P}(\mathrm{R}))$ is asymmetric. It is said to be consistent if there does not exist any $\mathrm{x}$ in $\mathrm{X}$ such that $(\mathrm{x}$, $\mathrm{x}) \in T^{\circ}(R)$.

Theorem 1 (Suzumura's Extension Theorem): If $R$ is a reflexive binary relation on $X$ then it has an extension $Q$ which is an order if and only if $R$ is consistent.

Proof: Since $\mathrm{T}(\mathrm{R})$ is transitive, it is clearly acyclic. Thus whenever $\mathrm{S}$ is a non-empty subset of $\mathrm{X}, \mathrm{M}(\mathrm{S}, \mathrm{T}(\mathrm{R}))$ is non-empty. Let $\mathrm{A}_{1}=M(X, T(R))$ 
and having defined $\mathrm{A}_{n}$, let $A_{n+1}=M\left(X \backslash \bigcup_{i=1}^{n} A_{i}, T(R)\right)$. Since $\mathrm{X}$ is finite, there exists a positive integer $\mathrm{r}$ such that $A_{r} \neq \phi$ and $X=\bigcup_{i=1}^{r} A_{i}$. Further if $i \neq j$, then $A_{i} \cap A_{j}=\phi$. Define $\mathrm{f}: \mathrm{X} \rightarrow \Re$ (the set of real numbers) as follows : $\mathrm{f}(\mathrm{x})=\mathrm{r}-\mathrm{i}+1$ if $\mathrm{x} \in \mathrm{A}_{i}$. Suppose $(\mathrm{x}, \mathrm{y}) \in \mathrm{P}(\mathrm{T}(\mathrm{R}))$. Then $\mathrm{x} \in \mathrm{A}_{i}, \mathrm{y} \in \mathrm{A}_{j}$ implies by our method of construction that $i<j$. Thus $f(x)>f(y)$. Now suppose $(\mathrm{x}, \mathrm{y}) \in \mathrm{T}(\mathrm{R})$ and towards a contradiction suppose that $f(y)>f(x)$. Hence if $\mathrm{y} \in \mathrm{A}_{j}$ and $\mathrm{x} \in \mathrm{A}_{i}$, clearly $j<i$. Thus, $A_{j}=M\left(X \backslash \bigcup_{k=1}^{j-1} A_{k}, T(R)\right), X \backslash \bigcup_{k=1}^{j-1} A_{j}$ is finite and $\mathrm{T}(\mathrm{R})$ is transitive implies that there exists $\mathrm{z} \in \mathrm{A}_{j}$ such that $(\mathrm{z}, \mathrm{x}) \in \mathrm{P}(\mathrm{T}(\mathrm{R}))$ since $\mathrm{x} \in$ $\left.\left(\mathrm{X} \backslash \bigcup_{k=1}^{j-1} A_{k}\right) \backslash A_{j}\right)$. By transitivity of $\mathrm{T}(\mathrm{R}),(\mathrm{z}, \mathrm{y}) \in \mathrm{P}(\mathrm{T}(\mathrm{R}))$, contradicting $\mathrm{y} \in \mathrm{A}_{j}$. Thus, $\mathrm{f}(\mathrm{x}) \geq \mathrm{f}(\mathrm{y})$. Let $(\mathrm{x}, \mathrm{y}) \in \mathrm{P}(\mathrm{R})$. Thus $(\mathrm{x}, \mathrm{y}) \in \mathrm{T}(\mathrm{R})$. If $(\mathrm{y}, \mathrm{x}) \in \mathrm{T}(\mathrm{R})$, then along with $(\mathrm{x}, \mathrm{y}) \in \mathrm{P}(\mathrm{R})$ it follows that $(y, y) \in$ $T^{\circ}(R)$ contradicting that $\mathrm{R}$ is consistent. Thus $(\mathrm{x}, \mathrm{y}) \in \mathrm{P}(\mathrm{T}(\mathrm{R}))$. Thus $f(x)>f(y)$. Now suppose that $(\mathrm{x}, \mathrm{y}) \in \mathrm{R}$ and towards a contradiction suppose that $f(y)>f(x)$. Then as before there exists $\mathrm{z} \in X$ such that $f(z)=f(y) \cdot(z, x) \in \mathrm{P}(\mathrm{T}(\mathrm{R}))$. Thus $(z, y) \in T^{\circ}(R)$. If $(\mathrm{y}, \mathrm{z}) \in \mathrm{T}(\mathrm{R})$ then $(z, z) \in T(R)$ contradicting the requirement that $\mathrm{R}$ is consistent. Thus, $(\mathrm{z}$, y) $\in \mathrm{P}(\mathrm{T}(\mathrm{R}))$. Thus, $f(z)>f(y)$ which contradicts $f(z)=f(y)$. Thus, $(x, y) \in \mathrm{R}$ implies $f(x) \geq f(y)$. Let $\mathrm{Q}=\{(\mathrm{x}, \mathrm{y}) \in \mathrm{X} \times \mathrm{X} / \mathrm{f}(\mathrm{x}) \geq \mathrm{f}(\mathrm{y})\}$. Thus, $\mathrm{Q}$ is an order which extends $\mathrm{R}$.

Corollary 1 (Szpilrajn's Extension Theorem): If $R$ is a partial order on $X$ then it has an extension $Q$ which is an order.

Proof: Follows easily from Suzumura's Extension Theorem by noting that a partial order is always consistent.

The following lemma proves useful in establishing subsequent results.

Lemma 1 Let $f: X \rightarrow \Re$ (the set of real numbers) be given. Then, there exists a positive integer $n$ and one to one functions $f_{i}: X \rightarrow N$ (:the set of natural numbers), $i \in\{1, \ldots, n\}$ such that $\{(x, y) \in X \times X / f(x) \geq f(y)\}=$ $\left\{(x, y) \in X \times X / f_{i}(x) \geq f_{i}(y)\right.$ for some $\left.i \in\{1, \ldots, n\}\right\}$.

Proof: Let $\{\mathrm{f}(\mathrm{x}) / \mathrm{x} \in \mathrm{X}\}=\left\{\mathrm{s}_{1}, \ldots, \mathrm{s}_{q}\right\}$ where $\mathrm{q}$ is a positive integer and $s_{j}<s_{j+1} \forall j \in\{1, \ldots, q-1\}$. Let $n_{j}=\left\{x \in X / f(x)=s_{j}\right\}$ and let $n=\left(n_{1}\right) ! \times \ldots \times\left(\mathrm{n}_{q}\right) !$

Let $\mathrm{g}: \mathrm{X} \rightarrow \mathrm{N}$ be defined as follows: $\mathrm{g}(\mathrm{x})=\mathrm{n}_{1}$, if $\mathrm{f}(\mathrm{x})=\mathrm{s}_{1}$ $\mathrm{g}(\mathrm{x})=\mathrm{n}_{1}+\ldots+\mathrm{n}_{j}$, if $\mathrm{f}(\mathrm{x})=\mathrm{s}_{j}$.

Clearly, $\forall \mathrm{x}, \mathrm{y} \in \mathrm{X}:[\mathrm{f}(\mathrm{x}) \geq \mathrm{f}(\mathrm{y})$ if and only if $[g(x) \geq g(y)]$. 
A function $\pi:\left\{1, \ldots, n_{1}+\ldots+n_{q}\right\} \rightarrow X$ is called a restricted permutation if $\forall k \in\left\{1, \ldots, n_{1}+\ldots+n_{q}\right\}:(1)\left[\pi(k) \in\left\{x \in X / f(x)=s_{1}\right\}\right.$ if and only $\left.\left(1 \leq k \leq n_{1}\right)\right] \&(2)\left[\pi(k) \in\left\{x \in X / f(x)=s_{i}\right\}\right.$ if and only $\left(n_{i-1} \leq k \leq n_{i}\right.$ and $1<i \leq q)]$. Let $\Pi$ denote the set of all restricted permutations. Since $\mathrm{X}$ is finite so is $\Pi$. For $\pi \in \Pi$, define $\mathrm{f}_{\pi}: \mathrm{X} \rightarrow\left\{1, \ldots, \mathrm{n}_{1}+\ldots+\mathrm{n}_{q}\right\}$ as follows: $\forall \mathrm{x} \in \mathrm{X}, \mathrm{f}_{\pi}(\mathrm{x})=\mathrm{k}$ if and only if $\pi(\mathrm{k})=\mathrm{x}$. It is now easy to verify that, $\{(\mathrm{x}, \mathrm{y}) \in \mathrm{X} \times \mathrm{X} / \mathrm{f}(\mathrm{x}) \geq \mathrm{f}(\mathrm{y})\}=\{(\mathrm{x}, \mathrm{y}) \in \mathrm{X} \times \mathrm{X} / \mathrm{g}(\mathrm{x}) \geq \mathrm{g}(\mathrm{y})\}=\{$ $(\mathrm{x}, \mathrm{y}) \in \mathrm{XxX} / \mathrm{f}_{\pi}(\mathrm{x}) \geq \mathrm{f}_{\pi}(\mathrm{y})$ for some $\left.\pi \in \Pi\right\}$. This proves the lemma.

The following theorem is rather interesting and to an extent original:

TheOREM 2 Let $P$ be any asymmetric binary relation on $X$. Then there exists a linear order $Q$ on $X$ such that $P \subset P(Q)$ if and only if $P$ is acyclic.

Proof: Suppose $\mathrm{P}$ is an asymmetric binary relation on $\mathrm{X}$ and suppose there exists a linear order $\mathrm{Q}$ on $\mathrm{X}$ such that $\mathrm{P} \subset \mathrm{P}(\mathrm{Q})$. Towards a contradiction suppose $P$ is not acyclic. Then there exists $x \in X$ such that $(x, x) \in T(P)$. Since $\mathrm{P} \subset \mathrm{P}(\mathrm{Q}),(\mathrm{x}, \mathrm{x}) \in \mathrm{T}(\mathrm{P}(\mathrm{Q}))$. Since $\mathrm{P}(\mathrm{Q})$ is transitive, $(\mathrm{x}, \mathrm{x}) \in \mathrm{P}(\mathrm{Q})$, contradicting the asymmetry of $\mathrm{P}(\mathrm{Q})$. Hence $\mathrm{P}$ must be acyclic.

Now suppose $\mathrm{P}$ is an asymmetric and acyclic binary relation on $\mathrm{X}$. Let $\mathrm{R}=\mathrm{T}(\mathrm{P} \cup \Delta)$. Clearly, $\mathrm{R}$ is reflexive and transitive. Hence by Szpilrajn's Extension Theorem there exists a reflexive, complete and transitive binary relation $\mathrm{L}$ on $\mathrm{X}$ such that $\mathrm{R} \subset \mathrm{L}$ and $\mathrm{P}(\mathrm{R}) \subset \mathrm{P}(\mathrm{L})$. Since $\mathrm{P}$ is asymmetric and acyclic $\mathrm{P} \subset \mathrm{P}(\mathrm{R})$. Hence $\mathrm{P} \subset \mathrm{P}(\mathrm{L})$.

Since $\mathrm{L}$ is transitive, it is clearly acyclic. Thus whenever $\mathrm{S}$ is a non-empty subset of $\mathrm{X}, \mathrm{M}(\mathrm{S}, \mathrm{L})$ is non-empty. Let $\mathrm{A}_{1}=\mathrm{M}(\mathrm{X}, \mathrm{L})$ and having defined $\mathrm{A}_{n}$, let $\mathrm{A}_{n+1}=\mathrm{M}\left(\mathrm{X} \backslash \bigcup_{i=1}^{n} A_{i}, L\right)$. Since $\mathrm{X}$ is finite, there exists a positive integer $\mathrm{r}$ such that $\mathrm{A}_{r} \neq \phi$ and $\mathrm{X}=\bigcup_{i=1}^{r} A_{i}$. Further if $\mathrm{i} \neq \mathrm{j}$, then $\mathrm{A}_{i} \cap$ $\mathrm{A}_{j}=\phi$. Define $\mathrm{f}: \mathrm{X} \rightarrow \Re$ (the set of real numbers) as follows $: \mathrm{f}(\mathrm{x})=\mathrm{r}$ $-\mathrm{i}+1$ if $\mathrm{x} \in \mathrm{A}_{i}$. Clearly, $\mathrm{L}=\{(\mathrm{x}, \mathrm{y}) \in \mathrm{X} \mathrm{x} \mathrm{X} / \mathrm{f}(\mathrm{x}) \geq \mathrm{f}(\mathrm{y})\}$. By Lemma 1 , there exists a positive integer $\mathrm{n}$ and one to one functions $\mathrm{f}_{i}: \mathrm{X} \rightarrow \mathrm{N}, \mathrm{i} \in\{1$, $\ldots, \mathrm{n}\}$ such that $\{(\mathrm{x}, \mathrm{y}) \in \mathrm{X} \times \mathrm{X} / \mathrm{f}(\mathrm{x}) \geq \mathrm{f}(\mathrm{y})\}=\left\{(\mathrm{x}, \mathrm{y}) \in \mathrm{X} \times \mathrm{X} / \mathrm{f}_{i}(\mathrm{x}) \geq\right.$ $\mathrm{f}_{i}(\mathrm{y})$ for some $\left.\mathrm{i} \in\{1, \ldots, \mathrm{n}\}\right\}$. For $\mathrm{i} \in\{1, \ldots, \mathrm{n}\}$, let $\mathrm{Q}_{i}=\{(\mathrm{x}, \mathrm{y}) \in \mathrm{X} \mathrm{x}$ $\left.\mathrm{X} / \mathrm{f}_{i}(\mathrm{x}) \geq \mathrm{f}_{i}(\mathrm{y})\right\}$. Now $(\mathrm{x}, \mathrm{y}) \in \mathrm{P}(\mathrm{L})$ implies and is implied by $f(x)>f(y)$ which is equivalent to $f_{i}(x)>f_{i}(y)$ for all $\left.\mathrm{i} \in\{1, \ldots, \mathrm{n}\}\right\}$. Thus $\mathrm{P}(\mathrm{L})=\cap$ $\left\{\mathrm{P}\left(\mathrm{Q}_{i}\right) / \mathrm{i} \in\{1, \ldots, \mathrm{n}\}\right\}$. Thus $\mathrm{P} \subset \mathrm{P}\left(\mathrm{Q}_{1}\right)$ where $\mathrm{Q}_{1}$ is a linear order on $\mathrm{X}$.

The following theorem, is really a consequence of two theorems in Aizerman and Malishevsky [1981] and these two theorems have been reproduced 
in Aizerman and Aleskerov [1995]. It is important enough to merit an independent proof.

THEOREM 3 If $R$ is a quasi-transitive binary relation then $P(R)=$ $\cap\{P(Q) / Q \in A\}$ where $\phi \neq A \subset\{Q \subset X \times X / Q$ is a linear order $\}$.

Proof: Let $\mathrm{P}=\mathrm{P}(\mathrm{R})$. $\mathrm{P}$ is asymmetric and transitive. Hence by Theorem 2 , there exists a linear order $\mathrm{R}^{1}$ on $\mathrm{X}$ such that $\mathrm{P} \subset \mathrm{P}\left(\mathrm{R}^{1}\right)$. Let $\mathrm{A}=\{\mathrm{Q} / \mathrm{Q}$ is a linear order on $\mathrm{X}$ with $\mathrm{P} \subset \mathrm{P}(\mathrm{Q})\}$. Thus, $\mathrm{P} \subset \cap\{\mathrm{P}(\mathrm{Q}) / \mathrm{Q} \in \mathrm{A}\}$.

Now suppose $(\mathrm{x}, \mathrm{y}) \in \cap\{\mathrm{P}(\mathrm{Q}) / \mathrm{Q} \in \mathrm{A}\}$. Towards a contradiction suppose $(\mathrm{x}, \mathrm{y}) \notin \mathrm{P}$. Since $(\mathrm{y}, \mathrm{x}) \in \mathrm{P} \subset \cap\{\mathrm{P}(\mathrm{Q}) / \mathrm{Q} \in \mathrm{A}\}$ contradicts $[(\mathrm{x}, \mathrm{y}) \in \mathrm{P}(\mathrm{Q})$ whenever $\mathrm{Q} \in \mathrm{A}]$, clearly $(\mathrm{y}, \mathrm{x}) \notin \mathrm{P}$. Further, $(\mathrm{x}, \mathrm{y}) \in \cap\{\mathrm{P}(\mathrm{Q}) / \mathrm{Q} \in \mathrm{A}\}$ implies $[(\mathrm{y}, \mathrm{x}) \notin \mathrm{P}(\mathrm{Q})$ whenever $\mathrm{Q} \in \mathrm{A}]$.

Let $\bar{P}=\mathrm{P} \cup\{(\mathrm{y}, \mathrm{x})\}$. Clearly, $\bar{P}$ is asymmetric. Suppose towards a contradiction that $(\mathrm{z}, \mathrm{z}) \in \mathrm{T}(\bar{P})$ for some $\mathrm{z} \in \mathrm{X}$. Thus there exists a positive integer $\mathrm{m}$ and elements $\mathrm{z}_{1}, \ldots, \mathrm{z}_{m}$ in $\mathrm{X}$ with $\mathrm{z}=\mathrm{z}_{1}=\mathrm{z}_{m}$ and $\left(\mathrm{z}_{i}, \mathrm{z}_{i+1}\right) \in$ $\mathrm{P} \cup\{(\mathrm{y}, \mathrm{x})\} \forall \mathrm{i} \in\{1, \ldots, \mathrm{m}-1\}$. If $\left(\mathrm{z}_{i}, \mathrm{z}_{i+1}\right) \in \mathrm{P} \forall \mathrm{i} \in\{1, \ldots, \mathrm{m}-1\}$, then we get by transitivity of $\mathrm{P}$, that $\left(\mathrm{z}_{1}, \mathrm{z}_{m}\right) \in \mathrm{P}(\mathrm{R})$ i.e. $(\mathrm{z}, \mathrm{z}) \in \mathrm{P}$, contradicting asymmetry of $\mathrm{P}$. Hence $\left(\mathrm{z}_{i}, \mathrm{z}_{i+1}\right)=(\mathrm{y}, \mathrm{x})$ for some $\mathrm{i} \in\{1, \ldots, \mathrm{m}-1\}$.

Observe that ' $\mathrm{m}$ ' is greater than three, for if $\mathrm{m} \leq 3$, then $\left(\mathrm{z}_{1}, \mathrm{z}_{2}\right)$ and $\left(\mathrm{z}_{2}, \mathrm{z}_{1}\right)$ belong to $\mathrm{P} \cup\{(\mathrm{y}, \mathrm{x})\}$ which is not possible since by hypothesis $\mathrm{x}$ $\neq \mathrm{y}$ and $(\mathrm{x}, \mathrm{y})$ does not belong to $\mathrm{P}(\mathrm{R})$.

Case 1: Cardinality of $\left.\left\{\mathrm{i} \in\{1, \ldots, \mathrm{m}-1\} /\left(\mathrm{z}_{i}, \mathrm{z}_{i+1}\right)\right\}=(\mathrm{y}, \mathrm{x})\right\}$ is one.

If $\left(\mathrm{z}_{1}, \mathrm{z}_{2}\right)=(\mathrm{y}, \mathrm{x})$, then $\mathrm{z}_{m}=\mathrm{y}$ implies by transitivity of $\mathrm{P}$ that $(\mathrm{x}, \mathrm{y})$ $\in \mathrm{P}$ which is a contradiction.

If $\mathrm{i}>1$, then $\left(\mathrm{z}_{1}, \mathrm{y}\right) \in \mathrm{P}$ and $\left(\mathrm{x}, \mathrm{z}_{1}\right) \in \mathrm{P}$ by transitivity of $\mathrm{P}$, so that $(\mathrm{x}$, y) $\in \mathrm{P}$ by transitivity of $\mathrm{P}$ which is a contradiction.

Case 2: Cardinality of $\left\{\mathrm{i} \in\{1, \ldots, \mathrm{m}-1\} /\left(\mathrm{z}_{i}, \mathrm{z}_{i+1}\right)=(\mathrm{y}, \mathrm{x})\right.$ is greater than one.

Let $\mathrm{j}=\min \left\{\mathrm{i} \in\{1, \ldots, \mathrm{m}-1\} /\left(\mathrm{z}_{i}, \mathrm{z}_{i+1}\right)=(\mathrm{y}, \mathrm{x})\right\}$ and $\mathrm{k}=\min \{\mathrm{i} \in\{\mathrm{j}+1$, $\left.\ldots, \mathrm{m}-1\} /\left(\mathrm{z}_{i}, \mathrm{z}_{i+1}\right)=(\mathrm{y}, \mathrm{x})\right\}$. Thus $\mathrm{z}_{j+1}=\mathrm{x}, \mathrm{z}_{k}=\mathrm{y}$ and by transitivity of $\mathrm{P},(\mathrm{x}, \mathrm{y}) \in \mathrm{P}$ which is a contradiction.

Thus $(\mathrm{z}, \mathrm{z}) \notin \mathrm{T}(\bar{P})$ whenever $\mathrm{z} \in \mathrm{X}$. Thus, $\bar{P}$ is acyclic. By Theorem 2 , there exists a linear order $\mathrm{R}^{\circ}$ such that $\bar{P} \subset P\left(R^{\circ}\right)$. Thus $\mathrm{P} \subset \bar{P} \subset P\left(R^{\circ}\right)$ and hence $R^{\circ} \in \mathrm{A}$. However, $(\mathrm{y}, \mathrm{x}) \in \bar{P}$ implies $(\mathrm{y}, \mathrm{x}) \in P\left(R^{\circ}\right)$. This contradicts $(\mathrm{x}, \mathrm{y}) \in \cap\{\mathrm{P}(\mathrm{Q}) / \mathrm{Q} \in \mathrm{A}\}$. Thus $(\mathrm{x}, \mathrm{y}) \in \mathrm{P}$. Hence the proof is complete.

The following well known theorem due to Dushnik and Miller [1941] follows as an immediate corollary of Theorem 3:

THEOREM 4 Let $P$ be any asymmetric and transitive binary relation on $X$. Then $P=\cap\{P(Q) / Q \in B\}$, where, $\phi \neq B \subset\{Q \in X \times X / Q$ is a linear order\}. 


\section{Batch Choice Functions}

Given any non-empty subset $\mathrm{S}$ of $\mathrm{X}$, let [S] denote the set of all non-empty subsets of $\mathrm{S}$. Hence in particular, $[\mathrm{X}]$ denotes the set of all non-empty subsets of $\mathrm{X}$. A choice function $\mathrm{C}$ on $\mathrm{X}$ is a function $C:[X] \rightarrow[X]$ such that $C(S) \subset S \forall S \in[X]$.

A choice function $\mathrm{C}$ on $\mathrm{X}$ is said to satisfy the Choice Acyclicity Property (CAP) if there does not exist a positive integer $\mathrm{K}$ and sets $\mathrm{S}_{1}, \ldots, \mathrm{S}_{K} \in$ $[\mathrm{X}]$ such that : (i) $\forall \mathrm{i} \in\{1, \ldots, \mathrm{K}-1\}: \mathrm{C}\left(\mathrm{S}_{i}\right) \in\left[\mathrm{S}_{i+1}\right] \backslash\left\{\mathrm{C}\left(\mathrm{S}_{i+1}\right)\right\}$; and (ii) $\mathrm{C}\left(\mathrm{S}_{K}\right) \in\left[\mathrm{S}_{1}\right] \backslash\left\{\mathrm{C}\left(\mathrm{S}_{1}\right)\right\}$.

A choice function $\mathrm{C}$ on $\mathrm{X}$ is said to be a batch choice function if there exists a linear order $\mathrm{Q}$ on $[\mathrm{X}]$ such that $\forall \mathrm{S} \in[\mathrm{X}], \mathrm{C}(\mathrm{S})=\{\mathrm{A} \in[\mathrm{S}] / \forall \mathrm{B} \in[\mathrm{S}]$ $:(\mathrm{A}, \mathrm{B}) \in \mathrm{Q}\}$.

Theorem 5 (Lahiri [1999]) $C$ is a batch choice function if and only if $C$ satisfies CAP.

Proof: If $\mathrm{C}$ is a batch choice function it clearly satisfies CAP. Hence suppose $\mathrm{C}$ satisfies CAP. If $\mathrm{X}$ has just one element then $\mathrm{C}$ is obviously a batch choice function. Hence suppose that $\mathrm{X}$ has atleast two elements. Let $\mathrm{P}=\{(\mathrm{C}(\mathrm{S}), \mathrm{A}) / \mathrm{A} \in[\mathrm{S}] \backslash\} \mathrm{C}(\mathrm{S})\}, \mathrm{S} \in[\mathrm{X}]$ and $\mathrm{S}$ has atleast two elements $\}$. Clearly $\mathrm{P}$ is asymmetric. Further, since $\mathrm{C}$ satisfies CAP, $\mathrm{P}$ is acyclic. By Theorem 2, there exists a linear order $\mathrm{Q}$ on $[\mathrm{X}]$ such that $\mathrm{P} \subset \mathrm{P}(\mathrm{Q})$. Given $\mathrm{S} \in[\mathrm{X}]$, since $(\mathrm{C}(\mathrm{S}), \mathrm{A}) \in \mathrm{P} \forall \mathrm{A} \in[\mathrm{S}] \backslash\{\mathrm{C}(\mathrm{S})\}, \mathrm{C}(\mathrm{S})$ $=\{\mathrm{A} \in[\mathrm{S}] / \forall \mathrm{B} \in[\mathrm{S}]:(\mathrm{A}, \mathrm{B}) \in \mathrm{Q}\}$. Thus, $\mathrm{C}$ is a batch choice function.

Remark 1: It is worth observing that there exists a choice function $\mathrm{C}$ on $X$ which does not satisfy the CAP and yet there does not exist sets $S_{1}, S_{2} \in$ $[\mathrm{X}]$ such that : (i) $\mathrm{C}\left(\mathrm{S}_{1}\right) \in\left[\mathrm{S}_{2}\right] \backslash\left\{\mathrm{C}\left(\mathrm{S}_{2}\right)\right\}$ and (ii) $\mathrm{C}\left(\mathrm{S}_{2}\right) \in\left[\mathrm{S}_{1}\right] \backslash\left\{\mathrm{C}\left(\mathrm{S}_{1}\right)\right\}$.

Example: Let $X=\{x, y, z\}$. Let $C(\{x, y\})=\{y\}, C(\{y, z\})=\{z\}$, $C \overline{(\{x, z\})}=\{z\}, C(A)=A$, otherwise. Clearly, there does not exist sets $S_{1}, S_{2} \in[X]$ such that : (i) $C\left(S_{1}\right) \in\left[S_{2}\right] \backslash\left\{C\left(S_{2}\right)\right\}$ and (ii) $C\left(S_{2}\right) \subset$ $\left[S_{1}\right] \backslash\left\{C\left(S_{1}\right)\right\}$.

However C does not satisfy CAP: $C(\{x, y\}) \in[\{y, z\}] \backslash\{C(\{y, z\})\}, C(\{y, z\}) \in$ $[\{x, z\}] \backslash\{C(\{x, z\})\}$ and $C(\{x, z\}) \in[\{x, y\}] \backslash\{C(\{x, y\})\}$. Towards a contradiction suppose there exists an order $\mathrm{Q}$ on $[\mathrm{X}]$ such that $\forall S \in[X]$, $C(S)=\{A \in[S] / \forall B \in[S]:(A, B) \in Q\}$. Then, $(\{y\},\{x\}) \in P(Q)$, $(\{x\},\{z\}) \in P(Q)$ and $(\{z\},\{y\}) \in P(Q)$ contradicting the assumption that $\mathrm{Q}$ is an order on $[\mathrm{X}]$. Thus $\mathrm{C}$ is not a batch choice function. 


\section{Functional Acyclicity}

The following property in Aizerman and Aleskerov [1995] known as functional acyclicity implies CAP:

A choice function $\mathrm{C}$ on $\mathrm{X}$ is said to satisfy Functional Acyclicity (FA) if there does not exist a positive integer $\mathrm{K}$ and sets $S_{1}, \ldots, S_{K} \in[X]$ such that : (i) $\forall i \in\{1, \ldots, K-1\}: C\left(S_{i}\right) \cap\left(S_{i+1} \backslash C\left(S_{i+1}\right)\right) \neq \phi$; and (ii) $C\left(S_{K}\right) \cap\left(S_{1} \backslash C\left(S_{1}\right)\right) \neq \phi$. However the following example reveals that the converse need not be true:

Example: Let $X=\{x, y, z\}$. Let $C(X)=\{x, y\}, C(\{x, z\})=\{z\}$ and $C \overline{(A)=A}$ otherwise. Clearly, C satisfies CAP. However, $(\mathrm{X} \backslash \mathrm{C}(\mathrm{X})) \cap\{\mathrm{x}$, $\mathrm{z}\} \neq \phi$ and $(\{x, z\} \backslash C(\{x, z\})) \cap X \neq \phi$ contradicting FA.

A choice function $\mathrm{C}$ is said to be a threshold choice function if there exists a function $\mathrm{V}:[\mathrm{X}] \rightarrow \mathrm{X}$ and a linear order $\mathrm{Q}$ such that : (i) $\forall \mathrm{S} \in[\mathrm{X}]$ : $\mathrm{V}(\mathrm{S}) \in \mathrm{S}$;(ii) $C(S)=\{x \in S /(x, V(S)) \in Q\}$.

The following theorem is equivalent to Theorem 3.15 in Aizerman and Aleskerov [1995] but unlike others we prove it here by appealing to Theorem 2.

THEOREM 6 A choice correspondence $C$ is a threshold choice function if and only if it satisfies FA.

Proof: Let $\mathrm{C}$ be a threshold choice function. Thus, there exists a function $\mathrm{V}:[\mathrm{X}] \rightarrow \mathrm{X}$ and a linear order Q such that : (i) $\forall \mathrm{S} \in[\mathrm{X}]: \mathrm{V}(\mathrm{S}) \in \mathrm{S}$; (ii) $C(S)=$ $\{x \in S /(x, V(S)) \in Q\}$. Towards a contradiction suppose that there exists a positive integer $\mathrm{K}$ and sets $\mathrm{S}_{1}, \ldots, \mathrm{S}_{K} \in[\mathrm{X}]$ such that : (i) $\forall \mathrm{i} \in\{1$, $\ldots, \mathrm{K}-1\}: \mathrm{C}\left(\mathrm{S}_{i}\right) \cap\left(\mathrm{S}_{i+1} \backslash \mathrm{C}\left(\mathrm{S}_{i+1}\right)\right) \neq \phi$; and (ii) $\mathrm{C}\left(\mathrm{S}_{K}\right) \cap\left(\mathrm{S}_{1} \backslash \mathrm{C}\left(\mathrm{S}_{1}\right)\right) \neq \phi$. Let $\mathrm{x}_{t} \in \mathrm{C}\left(\mathrm{S}_{t}\right) \cap\left(\mathrm{S}_{t+1} \backslash \mathrm{C}\left(\mathrm{S}_{t+1}\right)\right)$, for $\mathrm{t}=1, \ldots, \mathrm{K}-1$ and let $\mathrm{x}_{K} \in \mathrm{C}\left(\mathrm{S}_{K}\right) \cap$ $\left(\mathrm{S}_{1} \backslash \mathrm{C}\left(\mathrm{S}_{1}\right)\right)$. Thus $\left(\mathrm{x}_{t}, \mathrm{~V}\left(\mathrm{~S}_{t}\right)\right) \in \mathrm{Q}$, for $\mathrm{t}=1, \ldots, \mathrm{K},\left(\mathrm{V}\left(\mathrm{S}_{t+1}\right), \mathrm{x}_{t}\right) \in \mathrm{P}(\mathrm{Q})$ for $\mathrm{t}=1, \ldots, \mathrm{K}-1$, and $\left(\mathrm{V}\left(\mathrm{S}_{1}\right), \mathrm{x}_{K}\right) \in \mathrm{P}(\mathrm{Q})$. Since $\mathrm{Q}$ is transitive we get $\left(\mathrm{x}_{K}, \mathrm{x}_{K}\right) \in \mathrm{P}(\mathrm{Q})$, contradicting the asymmetry of $\mathrm{P}(\mathrm{Q})$. This contradiction implies that $\mathrm{C}$ must satisfy FA.

Now suppose that $\mathrm{C}$ satisfies FA. Let $\mathrm{P}=\{\mathrm{C}(\mathrm{S}) \mathrm{x}(\mathrm{S} \backslash \mathrm{C}(\mathrm{S}) / \mathrm{S} \in[\mathrm{X}]\}$. $\mathrm{P}$ is asymmetric and by Functional Acyclicity $\mathrm{P}$ is acyclic. By Theorem 2, there exists a linear order $\mathrm{Q}$ on $\mathrm{X}$ such that $\mathrm{P} \subset \mathrm{P}(\mathrm{Q})$.

Given $\mathrm{S} \in[\mathrm{X}]$, let $\{\mathrm{V}(\mathrm{S})\}=\{\mathrm{x} \in \mathrm{C}(\mathrm{S}) / \forall \mathrm{y} \in \mathrm{C}(\mathrm{S}):(\mathrm{y}, \mathrm{x}) \in \mathrm{Q}\}$.

Clearly, if $\mathrm{x} \in \mathrm{C}(\mathrm{S})$ then $(\mathrm{x}, \mathrm{V}(\mathrm{S})) \in \mathrm{Q}$. Now, suppose $\mathrm{x} \in \mathrm{S}$ and $(\mathrm{x}$, $\mathrm{V}(\mathrm{S})) \in \mathrm{Q}$ and towards a contradiction suppose $\mathrm{x} \notin \mathrm{C}(\mathrm{S})$. Thus, $(\mathrm{V}(\mathrm{S}), \mathrm{x}) \in$ $\mathrm{P}$. Thus by the above $(\mathrm{V}(\mathrm{S}), \mathrm{x}) \in \mathrm{P}(\mathrm{Q})$ which contradicts $(\mathrm{x}, \mathrm{V}(\mathrm{S})) \in \mathrm{Q}$. Thus $\mathrm{x} \in \mathrm{S},(\mathrm{x}, \mathrm{V}(\mathrm{S})) \in \mathrm{Q}$ implies $\mathrm{x} \in \mathrm{C}(\mathrm{S})$. 


\section{Acknowledgments}

This paper arose out of the conversations that I had with Ahmet Alkan and David Gale concerning their research on stable matchings which they presented at the International Conference on Operations Research and Game Theory, held at the Indian Institute of Technology, Madras (Chennai) during January 3 to 7, 2000. I would like to thank them both and in particular Ahmet Alkan for helpful comments. I would also like to thank Yukihio Funaki and Fuad Aleskerov for subsequent discussions on this paper. However the sole responsibility for errors that might remain rests solely with the author.

\section{References}

1. M. A. Aizerman and F. Aleskerov. Theory of Choice. North Holland, 1995.

2. M. A. Aizerman and A.V. Malishevski. General Theory of Best Variants Choice: Some Aspects, IEEE Transactions on Automatic Control, Vol. AC-26, No:5, 10301040, 1981.

3. B. Dushnik and E.W. Miller. Partially ordered sets, Am. J. Math. 63, $600-610$, 1941.

4. S. Lahiri. Path Independence and Choice Acyclicity Property. Keio Economic Studies Vol.36, No. 2, 1999.

5. E. Szpilrajn. Sur l'extension de l'ordre partiel. Foundamata Mathematica 16: 386$389,1930$.

6. K. Suzumura. Rational Choice, Collective Decisions and Social Welfare. Cambridge University Press, 1983. 


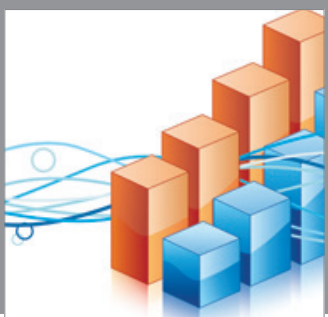

Advances in

Operations Research

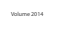

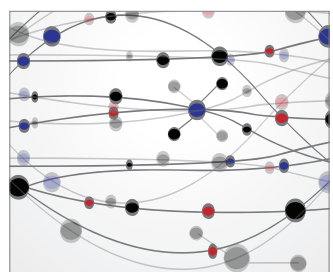

\section{The Scientific} World Journal
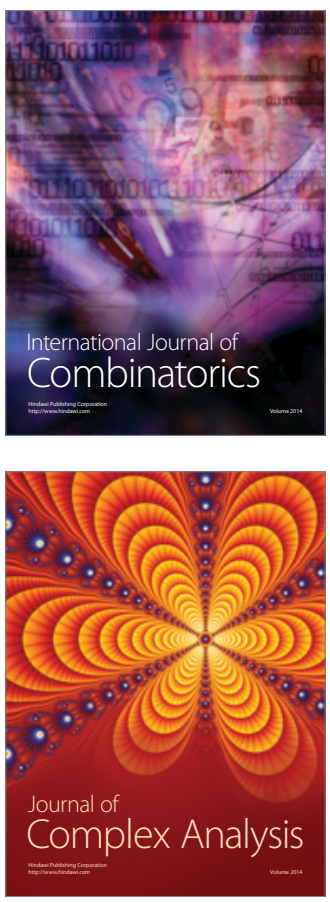

International Journal of

Mathematics and

Mathematical

Sciences
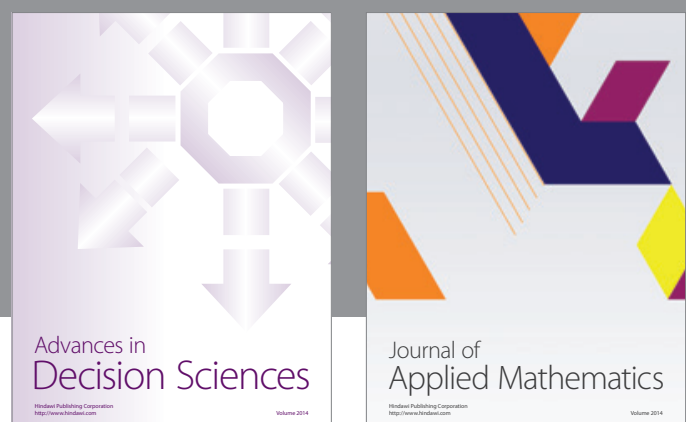

Journal of

Applied Mathematics
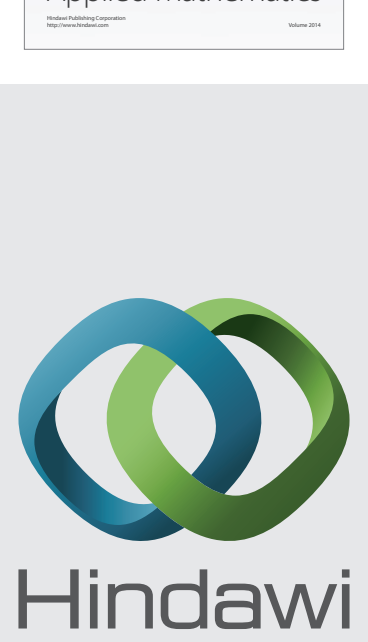

Submit your manuscripts at http://www.hindawi.com
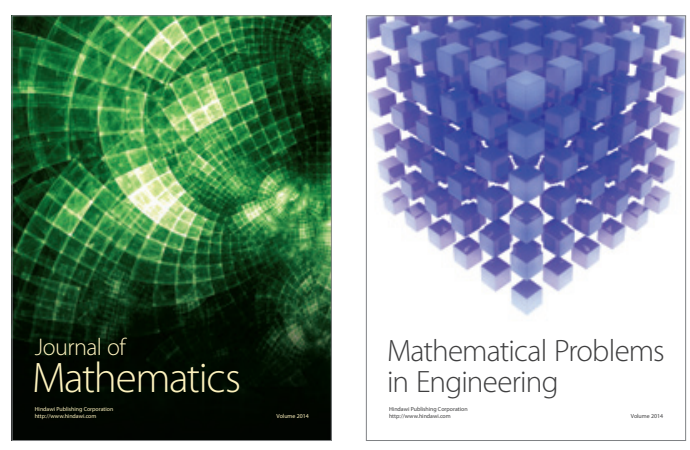

Mathematical Problems in Engineering
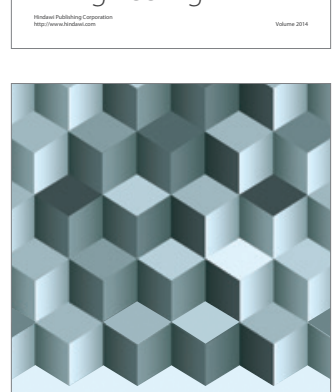

Journal of

Function Spaces
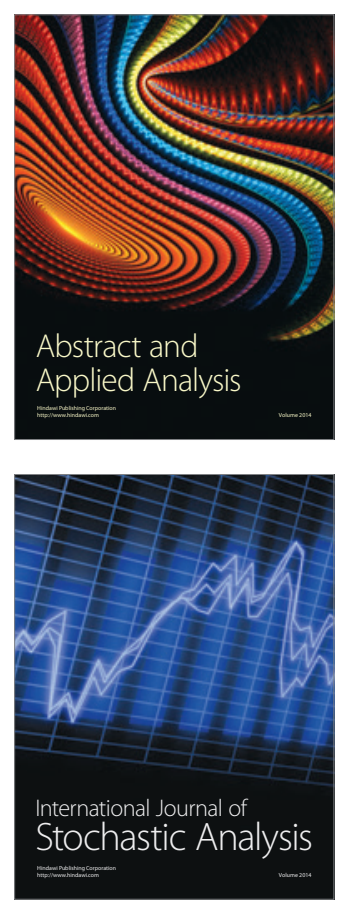

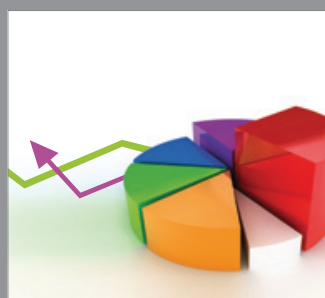

ournal of

Probability and Statistics

Promensencen
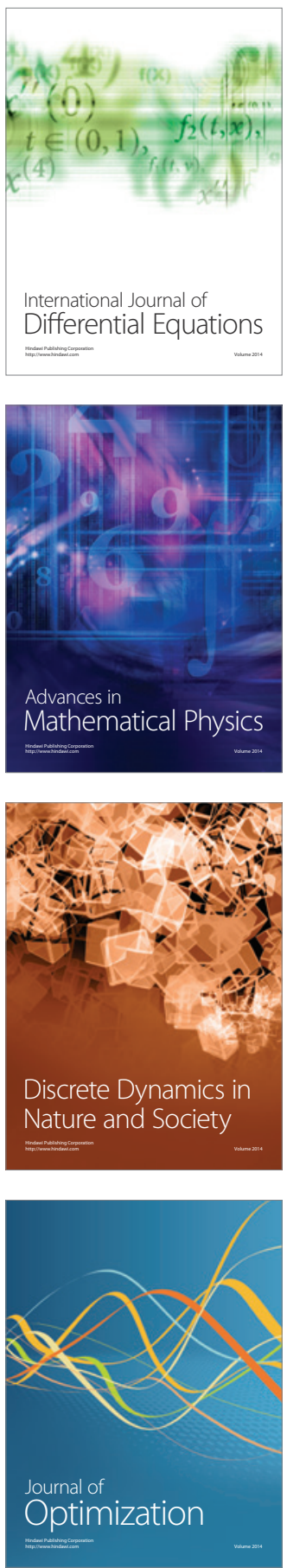